\title{
Article
}

\section{Internal validation of GlobalFilerTM kit using reduced reaction volume}

\author{
Almohammed, Eida Khalaf and Hadi, Ss \\ Available at http://clok.uclan.ac.uk/31407/ \\ Almohammed, Eida Khalaf and Hadi, Ss ORCID: 0000-0002-2994-3083 (2019) \\ Internal validation of GlobalFilerTM kit using reduced reaction volume. \\ Forensic Science International: Genetics Supplement Series, 7 (1). pp. 878- \\ 883. ISSN 1875-1768
}

It is advisable to refer to the publisher's version if you intend to cite from the work. http://dx.doi.org/10.1016/j.fsigss.2019.11.009

For more information about UCLan's research in this area go to http://www.uclan.ac.uk/researchgroups/ and search for < name of research Group>.

For information about Research generally at UCLan please go to http://www.uclan.ac.uk/research/

All outputs in CLoK are protected by Intellectual Property Rights law, including Copyright law. Copyright, IPR and Moral Rights for the works on this site are retained by the individual authors and/or other copyright owners. Terms and conditions for use of this material are defined in the policies page.

\section{CLoK}

Central Lancashire online Knowledge www.clok.uclan.ac.uk

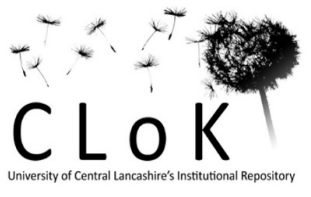




\title{
Page 1 of 5
}

Internal Validation of GlobalFiler ${ }^{\mathrm{TM}}$ Kit Using Reduced Reaction Volume

\author{
Almohammed. $\mathrm{E}^{1^{*}, 2 *} ;$ Hadi. $\mathrm{S}^{1^{*}}$ \\ ${ }^{1}$ University of Central Lancashire, School of Forensics and Applied Sciences, Preston, UK \\ ${ }^{2}$ Ministry of Interior of Qatar, Doha, Qatar; \\ *Corresponding author: \\ eida-k-al@hotmail.com
}

Keywords: GlobalFiler ${ }^{\mathrm{TM}}$;Qatar; Validation

\section{Introduction}

The GlobalFilerTM kit amplifies 21 autosomal loci including CODIS extended set of STR loci. The kit was designed to combine 21 autosomal STR loci (1), (12). Thus, GlobalFiler ${ }^{\mathrm{TM}}$ combines the CODIS extended set of loci and includes seven autosomal STR loci from the expanded European Standard Set of Loci (ESSL). The kit also includes the highly discriminating SE33 locus. For enabling the use of the kit in the Forensic Laboratories and this project, an internal validation of GlobalFilerTM kit was carried out to test the robustness of this kit through a range of studies in accordance with SGWDAM guidelines (10). Reference and real casework samples previously tested using Identifiler ${ }^{\circledR}$ Plus autosomal STR kit were used. In this study, the experiments, recommended by SWGDAM, conducted in order to demonstrate the performance of GlobalFiler ${ }^{\mathrm{TM}}$ kit and their results are presented.

Keywords: Globalfiler; Autosomal STR; Validation; Forensic; Qatar.

\section{Materials and Methods}

\subsection{Samples Collection and Extraction}

The samples were extracted using the QIAamp ${ }^{\circledR}$ extraction DNA Mini protocol (Qiagen). The extraction procedure and Quantifiler $^{\circledR}$ Trio DNA Quantification kit were followed in accordance with manufacturer's recommendation. Ethical approval was granted by Ministry of Interior of Qatar and University of Central Lancashire "Ref STEM454” for the PhD project.

\subsection{PCR Amplification \& Capillary Electrophoresis}

Two PCR amplification reactions were tested in this study following the PCR setup proportions recommended by the GlobalFiler TM PCR Amplification kit user guide. A full volume PCR of $25 \mu 1$ was compared with a half volume PCR of 12.5 $\mu 1$. Amplified samples were prepared for fragment analysis in capillary electrophoresis in capillary array ABI 3500 Genetic Analyzer.

\subsection{Minimum Threshold Calculation}

Data from 55 negative amplification controls were used to assess baseline noise and calculate a minimum detection and quantitation thresholds for the GlobalFiler ${ }^{\mathrm{TM}}$ PCR kit at 29 cycles.

\subsection{Half Volume PCR Reaction Validation}

In order to evaluate the PCR reaction of both GlobalFiler ${ }^{\mathrm{TM}}$, half volume experiment was conducted by amplifying 10 samples that had been profiled previously with a full volume reaction. The positive DNA controls of 2800M, 9947A and the 10 Male DNA sample, were prepared and analysed parallel with serial dilutions reactions.

\subsection{Sensitivity Study Using Half Volume PCR}

Two DNA control samples, 9947A and positive control 007, were used in the sensitivity study. A serial dilution of the samples was prepared having DNA amounts of $1 \mathrm{ng}, 750 \mathrm{pg}, 500 \mathrm{pg}, 250 \mathrm{pg}, 125 \mathrm{pg}, 62.5 \mathrm{pg}, 31.25 \mathrm{and} 15 \mathrm{pg}$. These were amplified, in triplicate.

\subsection{Precision, Reproducibility and Accuracy Studies}

A total of 11 unrelated male samples including 2800, 9947A positive DNA control were used for the precision and accuracy study. Results from three different runs were analysed and compared to allelic ladder. Mean allele size and standard deviations were determined over three different runs and compared with the allelic ladder in order to illustrate the precision and accuracy of sample analysis.

\subsection{Female/Male, Male/Male DNA sample Mixture}




\section{Page 2 of 5}

In the internal validation of GlobalFiler ${ }^{\mathrm{TM}}$ kit, a mixed male/female DNA controls (DNA 007 and 9947A and 2800) with known ratios were tested in triplicate. The mixture ratios included 1:1, 1:3, 3:1, 1:9, 9:1, 1:19 and 19:1, for 1 ng of mixed template DNA in triplicate.

\subsection{Casework Samples Study}

A total of 64 forensics DNA samples were used in this study. The casework samples from cases received in forensic Laboratory were used to assess the GlobalFiler ${ }^{\mathrm{TM}}$ kit. All samples were previously extracted using different extraction methods, and quantified using Quantifiler ${ }^{\circledR}$ Trio kit and profiled previously with Identifiler Plus ${ }^{\mathrm{TM}}$ kit. $^{\circ}$

\subsection{Stutter Analysis}

Stutter percentages were calculated at each locus. This was previously analysed using 100 samples used for allele range determination experiment. Stutter percentages were calculated for each locus by dividing the stutter peak height by the parent peak height and multiplying it by 100 .

\subsection{Species Specificity Study}

Non-human samples extracts were provided by UCLAN lab, which include dog, pig, horse, chicken, mouse, and rat.

\section{Results}

\subsection{Assessment of Limit of detection (LOD and Limit of quantitation (LOQ) Thresholds}

The average height and standard deviation of peaks generated from 55 negative controls were calculated after adjusting the peak amplitude threshold to 1 relative fluorescent unit (RFU) to capture all data points. The highest limit of detection (LOQ) value was calculated as 50 RFU for the Purple (SID ${ }^{\mathrm{TM}}$ ) dye (Fig 1).

\subsection{Sensitivity Study}

DNA serial dilutions (from 1 ng to $15.6 \mathrm{pg}$ ) were analysed at a threshold of 50 RFU. Full allele profiles were obtained for 9947A and 007 down to a level of $62.5 \mathrm{pg}$. The highest value was $2100 \mathrm{RFU}$ for vWA at $62.25 \mathrm{pg}$ of DNA input. Therefore, the minimum peak height for homozygous was set to $800 \mathrm{RFU}$ in the peak quality tab of the analysis method editor of the GeneMapper ${ }^{\circledR}$ ID-X Software v1.5, when analysing low template DNA samples in other studies. Below 125 pg of DNA input, a variable dropout of alleles was observed (Fig 3).

\subsection{Species specificity}

in this study, the focus was on the possible cross reactivity of GlobalFilerTM kit against animal DNA commonly since forensic samples might originate in many cases from environments rich in such DNA. Negative results were obtained at a 50 RFU threshold for all of cat, mouse, chicken samples tested demonstrating the specificity of the GlobalFiler ${ }^{\mathrm{TM}}$ kit against these species. However, some low peaks were observed in dog, sheep, pig, rabbit, and rat samples (Fig 4).

\subsection{PCR with reduced reaction volume for reference samples}

The genotypes of all controls showed expected results. The reduction of the reaction volume by half for the analysis of reference DNA samples with known DNA content, was evaluated using 10 human genomic DNA from saliva samples at a DNA input of $0.5 \mathrm{ng}$. The results demonstrated reliable performance from reduced reaction volume. Majority of STR markers showed higher peak intensities in the reduced reaction volume reaction as compared to a parallel full volumes reaction (Fig 2).

\subsection{Reproducibility and Robustness Study}

To investigate the consistency of the GlobalFiler ${ }^{\mathrm{TM}}$ kit, each of the 10 male DNA samples, including the positive controls 2800M, 9947A, 007 were typed on 3 different occasions. Consistent profiles were obtained successfully for all samples genotyped using the GlobalFiler ${ }^{\mathrm{TM}}$ kit.

\subsection{Casework Sample Study}

The GlobalFiler ${ }^{\mathrm{TM}}$ kit was tested with DNA extracts obtained from casework sample extracts to evaluate the amplification efficiency GlobalFiler ${ }^{\mathrm{TM}}$ kit. The GlobalFiler ${ }^{\mathrm{TM}}$ typing results obtained from the set of 64 biological stains showed full allele concordance with the DNA profiling data previously obtained with Identifiler ${ }^{\circledR}$ Plus. Three different DNA extracts derived from stains on denim and leather that showed a successful result even when the values for the internal PCR control were high showing the presence of an inhibitor. This demonstrated increased tolerance of GlobalFilerTM PCR buffer against PCR inhibitors usually found in forensic samples compared to the buffers used in both the Identifiler ${ }^{\circledR}$ kit and the Quantifiler $^{\mathrm{TM}}$ trio DNA quantification kit.

\subsection{Mixture Study}

The results of the two DNA mixtures series (1 ng of total DNA) with relative ratios of 1:1, 1:3, 3:1, 1:9, 9:1, 1:19 and 19:1 of female (major component)/male (minor component) were collated. All the unique alleles of the minor contributor (full profiles) 


\section{Page 3 of 5}

were detected for the series. Regarding the male-specific Y-markers, most noted was the peak height decrease and the dropout observed at the DYS391 marker for series 19:1 and 19:1 compared to the Y-indel marker that was detected in all series (7), (11). In this case, all the unique alleles of the minor contributor (full profiles) were robustly detected until ratios of 09:01, which corresponded, with a total DNA input of the minor male component in the PCR of $273 \mathrm{pg}$.

\subsection{Stutter Thresholds for 21 Autosomal STRs Included in GlobalFiler TM STR Kit}

The percentage of the stutter product relative to the main allele and the standard deviation for each locus obtained from 100 human genomic DNA samples were calculated. The estimated stutter filters, were compared to stutter filter sets determined by published validation of the GlobalFiler ${ }^{\mathrm{TM}}$ kit (1). In our study, all loci showed little higher percentage of stutters when compared to those developed by the manufacturer. The loci D22S1045; locus SE33 and D2S1338 had highest percent stutters with maximum peak heights at $19.02 ; 19.45 \%$ and $18 \%$ of the main allele, respectively.

\subsection{Precision and Accuracy Study}

Allele sizing precision studies used 24 GlobalFiler ${ }^{\mathrm{TM}}$ allelic ladders across multiple injections in a 3500 platform. The highest variability in sizing observed for any allele of the GlobalFiler ${ }^{\mathrm{TM}}$ kit. Sizing accuracy between the allelic ladder peaks and the corresponding alleles in a set of 100 human genomic DNA reference samples and casework revealed that all alleles were sized within $0.5 \mathrm{bp}$ of their respective allelic ladder peaks.

\section{Discussion}

\subsection{Minimum Analytical Threshold Estimation}

Minimum analytical thresholds are minimum peak amplitude values that separates, true DNA peak signal from background noise, with a high degree of confidence. A published method to determine analytical thresholds was used. The peak amplitude threshold in the GeneMapper ID-X method was then set to the LOQ of the 'noisiest' dye channel Purple (SID ${ }^{\text {TM})}$ dye channel (1). With this consideration, the conservative value of 50 RFUs was chosen as the minimum thresholds.

\subsection{Sensitivity Study}

The results of sensitivity experiment demonstrated that the GlobalFiler ${ }^{\mathrm{TM}}$ kit was sensitive down to 31.5 pg of positive controls using 29 PCR cycles. Such sensitivity level was published earlier (6). This sensitivity study indicated that the GlobalFiler ${ }^{\mathrm{TM}}$ kit is sensitive and suitable for low template DNA samples (6), (3). Full profiles were obtained from (31.25 pg to $15.5 \mathrm{pg}$ dilution) when an analytical threshold of 100 RFU was used. Thus, allele calls below 200 RFU were further analysed to demonstrate reproducibility above 200 RFU. Similar minimum detection thresholds (100-120 RFUs) had been previously validated for the application of GlobalFiler ${ }^{\mathrm{TM}}$ kit to the analysis of reference DNA (3).

\subsection{Species specificity}

GlobalFiler ${ }^{\mathrm{TM}}$ species specificity against animal DNAs was used in order to check if possible cross reactivity of GlobalFiler ${ }^{\mathrm{TM}}$ can occur. As DNA from non-human species may be present on forensic evidentiary material, this kit was tested with various kinds of non-human DNA to evaluate any PCR products. However, any potential cross reactivity with non-human species should be known so that profiles can be analysed correctly and considerations should be taken if necessary (3), (5). Comparing the results of this experiment with previously published data, all markers previously found to amplify in few peaks were confirmed in this study as well.

\subsection{PCR with reduced reaction volume for reference samples}

The reduction of the reaction volume by half for the analysis of reference DNA samples with known DNA content as a costeffective measure, was evaluated. Results indicate that half-reaction amplification $(12.5 \mu \mathrm{L})$ using GlobalFiler ${ }^{\mathrm{TM}}$ produced similar. Half reaction amplifications were more sensitive and allowed for the amplification of less DNA template in line with previous work (4).

\subsection{Reproducibility}

Fully concordant results were obtained by three analysis of 3 replicates of 8 human genomic DNA samples with known STR profiles using $0.5 \mathrm{ng}$ of genomic DNA input, demonstrating the reproducibility and the repeatability of the GlobalFiler ${ }^{\mathrm{TM}}$ kit (12). A reproducibility study ensures that profiles developed with the amplification kit were reliable and suitable.

\subsection{Casework Study}

The ability to obtain reliable results from samples encountered as casework was assessed by GlobalFiler ${ }^{\mathrm{TM}}$. Mixtures, low template amount, degradation, and inhibition can all impact results and interpretation of data from case-type samples. A total 


\section{Page 4 of 5}

of 64 samples tested as a part of this study represented, quality, and quantity encountered with case-type samples. To sum up, GlobalFiler ${ }^{\mathrm{TM}}$ kit has proved highly efficient in analysing casework samples (9), (12).

\subsection{Mixture Study}

Mixtures are very common forensic samples and mixture studies is useful to mixture interpretation, including the number of contributors to the mixture, the major and minor contributor genotype. Although all alleles for major and minor contributors were detected in both sets of male/female and male/male mixture with 1:1, 1:3 and 3:1 ratios prepared, resolution of full profiles into minor and major contributors was not achievable with 1:9, 9:1, 1:19 and 19:1. All alleles were called for the 1:1 and 1:4 mixtures. At the 9:1 ratio, 81.5 88.9\% of all minor contributor alleles were detected with all 3 PCR replicates. For the 1:19 mixtures, some autosomal STR alleles dropped out.

\subsection{Precision and accuracy}

Since precision is critical for accurate genotyping of unknown amplified STR products, the allelic ladder of GlobalFiler ${ }^{\mathrm{TM}}$ was used to study the size precision of the assigned alleles. Precision study was also completed to ensure that sizing within an injection was consistent. The analyses showed no significant difference between standard deviations calculated (2), (8), (12).

\subsection{Stutter threshold}

Stutter peaks are natural by-products of PCR amplification in STR profiles, which involve the process of strand slippage. A minor peak with one repeat unit smaller or larger than the associated allele is commonly observed. It was observed in this study that, the percent stutter was usually more pronounced for shorter repeat motifs and generally increased with allele length.

\section{Conclusion}

These data demonstrate that the GlobalFiler ${ }^{\mathrm{TM}}$ PCR amplification kit generates high quality, reproducible, precise, accurate, and sensitive profiling STR data, even from sub-nanogram amounts of genomic DNA template from a variety of forensic samples including blood, semen and saliva stains, hair, muscle, tissues, bone and teeth. Analytical, stochastic and stutter threshold data were assessed for GlobalFiler ${ }^{\mathrm{TM}}$ in this study. The use of a half-reaction protocol would be operationally a robust method besides significant cost effectiveness.

\section{Conflict of Interest \\ None.}

\section{Supplementary Tables and Figures}

\section{Acknowledgment}

We would like to thank Ministry of Interior of Qatar for enabling grant support for this project. We also acknowledge Qatar embassy in the UK for supporting this project.

\section{References}

1.FLORES, S., SUN, J., KING, J. \& BUDOWLE, B. 2014. Internal validation of the GlobalFilerTM Express PCR Amplification Kit for the direct amplification of reference DNA samples on a high-throughput automated workflow. Forensic Science International: Genetics, 10, 33-39.

2.FRENCH, J. 2011. Implementation of the PowerPlex® 18D System in a Databasing Laboratory: Transforming Operations to Improve Efficiency. Available: http://www.promega.com/resources/articles/profiles-in-dna/2011/implementation-of-the-powerplex18d-system-in-a-databasing-laboratory/ [Accessed].

3.FUJII, K., WATAHIKI, H., MITA, Y., IWASHIMA, Y., KITAYAMA, T., NAKAHARA, H., MIZUNO, N. \& SEKIGUCHI, K. 2015. Allele frequencies for 21 autosomal short tandem repeat loci obtained using GlobalFiler in a sample of 1501 individuals from the Japanese population. Legal Medicine, 17, 306-308.

4.HOFFMAN, N. H. \& FENGER, T. 2010. Validation of Half-Reaction Amplification Using Promega PowerPlex® 16. Journal of forensic sciences, 55, 1044-1049.

5. KRENKE, B. E., VICUliS, L., RICHARD, M. L., PRINZ, M., MILNE, S. C., LADD, C., GROSS, A. M., GORNALL, T., FRAPPIER, J. R. H., EISENBERG, A. J., BARNA, C., ARANDA, X. G., ADAMOWICZ, M. S. \& BUDOWLE, B. 2005. Validation of a male-specific, 12-locus fluorescent short tandem repeat (STR) multiplex. Forensic Science International.

6. MARTÍN, P., DE SIMÓN, L. F., LUQUE, G., FARFÁN, M. J. \& ALONSO, A. 2014. Improving DNA data exchange: Validation studies on a single 6 dye STR kit with 24 loci. Forensic Science International: Genetics, 13, 68-78.

7. MUlERO, J. J., CHANG, C. W., CALANDRO, L. M., GREEN, R. L., LI, Y., JOHNSON, C. L. \& HENNESSY, L. K. 2006. Development and Validation of the AmpFLSTR Yfiler(R) PCR Amplification Kit: A Male Specific, Single Amplification 17 YSTR Multiplex System*. Journal of Forensic Sciences, 51, 64-75.

8. SMITH, R. 1995. Accurate size comparison of short tandem repeat alleles amplified by PCR. Biotechniques, 18, 122-128. 


\section{Page 5 of 5}

9. STEINLECHNER, M., BERGER, B., NIEDERSTATTER, H. \& PARSON, W. 2002. Rare failures in the amelogenin sex test. Int $J$ Legal Med, 116, 117 - 120.

10. THANGARAJ, K., REDDY, A. \& SINGH, L. 2002. Is the amelogenin gene reliable for gender identification in forensic casework and prenatal diagnosis? Int J Legal Med, 116, 121 - 123.

11. THOMPSON, J. M., EWING, M. M., FRANK, W. E., POGEMILLER, J. J., NOLDE, C. A., KOEHLER, D. J., SHAFFER, A. M., RABBACH, D. R., FULMER, P. M., SPRECHER, C. J. \& STORTS, D. R. 2013. Developmental validation of the PowerPlex-« Y23 System: A single multiplex Y-STR analysis system for casework and database samples. Forensic Science International: Genetics, 7, 240-250. 